\title{
Tracers confirm downward mixing of Tyrrhenian Sea upper waters associated with the Eastern Mediterranean Transient
}

\author{
W. Roether ${ }^{1}$ and J. E. Lupton ${ }^{2}$ \\ ${ }^{1}$ Institut für Umweltphysik, Univ. Bremen, Bremen, Germany \\ ${ }^{2}$ NOAA Pacific Marine Environmental Laboratory, Newport, OR 97365, USA
}

Received: 12 August 2010 - Published in Ocean Sci. Discuss.: 24 August 2010

Revised: 20 January 2011 - Accepted: 22 January 2011 - Published: 28 January 2011

\begin{abstract}
Observations of tritium and ${ }^{3} \mathrm{He}$ in the Tyrrhenian Sea, 1987-2009, confirm the enhanced vertical mixing of intermediate waters into the deep waters that has been noted and associated with the Eastern Mediterranean Transient in previous studies. Our evidence for the mixing rests on increasing tracer concentrations in the Tyrrhenian deep waters, accompanied by decreases in the upper waters, which are supplied from the Eastern Mediterranean. The downward transfer is particularly evident between 1987 and 1997. Later on, information partly rests on increasing tritium- ${ }^{3} \mathrm{He}$ ages; here we correct the observed ${ }^{3} \mathrm{He}$ for contributions released from the ocean floor. The Tyrrhenian tracer distributions are fully compatible with data upstream of the Sicily Strait and in the Western Mediterranean. The tracer data show that mixing reached to the bottom and confirm a cyclonic nature of the deep water circulation in the Tyrrhenian. They furthermore indicate that horizontal homogenization of the deep waters occurs on a time scale of roughly 5 years. Various features point to a reduced impact of Western Mediterranean Deep Water (WMDW) in the Tyrrhenian during the enhanced-mixing period. This is an important finding because it implies less upward mixing of WMDW, which has been named a major process to enable the WMDW to leave the Mediterranean via the Gibraltar Strait. On the other hand, the TDW outflow for several years represented a major influx of enhanced salinity and density waters into the deep-water range of the Western Mediterranean.
\end{abstract}

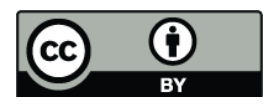

Correspondence to: W. Roether (wroether@physik.uni-bremen.de)

\section{Introduction}

Previous work has demonstrated that the Tyrrhenian Sea acts to mix intermediate-depth waters entering from the Eastern Mediterranean (EMed) with Western Mediterranean Deep Water (WMDW) (e.g., Hopkins, 1988; Astraldi et al., 1996). The mixing occurs primarily in the form of cascading at the southern slope of the sea (Sparnocchia et al., 1999), and it is of major relevance for the turnover of the WMDW (Millot, 1999). A special feature is a T-S staircase structure, which implies that the interior of the deep part of the sea is replenished laterally from the boundary (Zodiatis and Gasparini, 1996). More detail is provided in Sect. 2. A transient enhancement in the mixing, potentially modifying the role of the Tyrrhenian, has been noted and associated with the Eastern Mediterranean Transient (EMT; Roether et al., 2007) by Astraldi et al. (2002) and Gasparini et al. (2005). We here address the enhancement on the basis of helium isotope and tritium data.

The starting point of the present work has been a recent study, which observed the release of ${ }^{3} \mathrm{He}$, the rare isotope of helium (He), from the submarine volcanoes of the Aeolian Arc in the southern Tyrrhenian Sea (Lupton et al., 2011). Such He is derived from the Earth's deep interior. It has a ${ }^{3} \mathrm{He} /{ }^{4} \mathrm{He}$ ratio an order of magnitude higher than that in the atmosphere (atmospheric ratio $R_{\mathrm{a}}=1.384 \times 10^{-6}$; Clarke et al., 1976). Thus ${ }^{3} \mathrm{He}$ is a unique indicator of volcanic input. While the effect, in accordance with the depths of release, was essentially confined to $300-700 \mathrm{~m}$ depth, it was found to be superimposed on a ${ }^{3} \mathrm{He}$ background that increased downwards with maximum concentrations below $1000 \mathrm{~m}$ (Lupton et al., 2011). That difference in depth together with the rather moderate volcanic ${ }^{3} \mathrm{He}$ signals led the authors to conclude

Published by Copernicus Publications on behalf of the European Geosciences Union. 


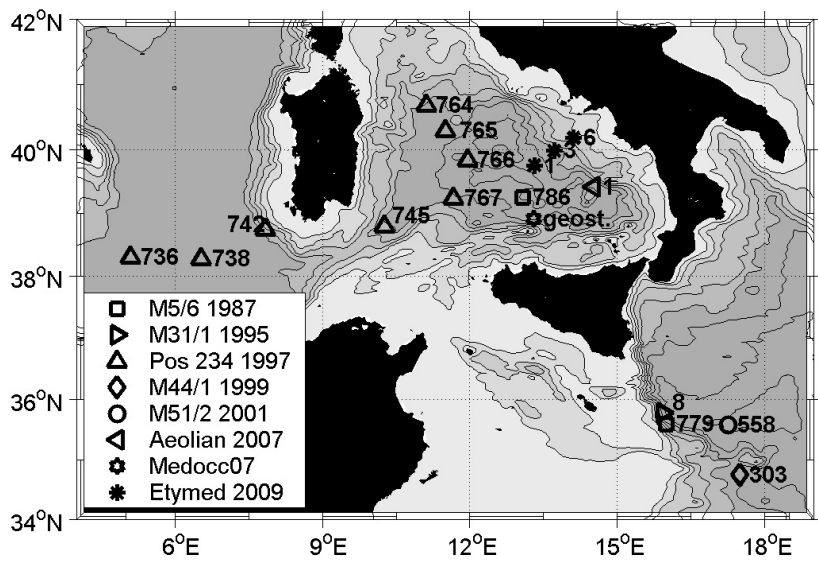

Fig. 1. Map of stations used in the present work. Station numbers are given next to the markings. For cruises see Table 1. Depth isolines are $500 \mathrm{~m}$ apart. Malta Escarpment = steep slope near 1995 Sta. 8; Sardinian Channel = deep connection between Tyrrhenian and WMed south of Sardinia.

that the deep signal was independent of the observed release, and instead was the result either of hydrothermal input elsewhere or of ingrowth from the decay of tritium. We here show that the latter source has indeed been dominant. We find that the deep-water ${ }^{3} \mathrm{He}$ maximum was generated by the mentioned enhanced mixing activity in the Tyrrhenian intermediate and deep waters. The available tritium and ${ }^{3} \mathrm{He}$ data, combined with suitable boundary conditions, give robust information on the process, independent of previous work.

In contrast to the Earth's deep interior, the shallower interior, i.e. the Earth's crust, sustains He production via $\alpha$-decay of uranium and thorium isotopes, which feeds an oceanbottom release of $\mathrm{He}$ depleted in ${ }^{3} \mathrm{He}$. At the ocean surface, $\mathrm{He}$ is essentially in solubility equilibrium with atmospheric He. Below we apply a procedure that allows a separation of the various He components (Sect. 3). Tritium is produced by cosmic radiation, but the dominant source over the past decades has been the atmospheric testing of nuclear weapons. As a consequence, its atmospheric concentrations strongly peaked in the 1960s and have since decreased by radioactive decay $\left(T_{1 / 2}=12.32\right.$ years; Lucas and Unterweger, 2000) and by exchange primarily with the ocean waters. From concurrent data of tritium and tritiugenic ${ }^{3} \mathrm{He}$ a water age (subsurface travel period; see Sect. 3) can be computed.

\section{The Tyrrhenian Sea: the pre-EMT situation and EMT-induced changes}

Classically, the Tyrrhenian Sea subsurface waters are composed of overflow at the Sicily Strait ( $500 \mathrm{~m}$ sill) from the Eastern Mediterranean Sea (EMed) (Sparnocchia et al., 1999) and of Western Mediterranean Deep Water (WMDW), which enters via the Sardinian Channel ( 1900 m sill; Fig. 1) at greater depths (Astraldi et al., 1996). Together they form the Tyrrhenian Deep Water (TDW), which leaves through the channel against the inflow of WMDW. The input from the Sicily Strait is topographically steered into the south of the sea. It is composed of Levantine Intermediate Water (LIW), which is formed in the northwestern Levantine Sea, and of waters adjoining the LIW from below. The latter waters, termed transitional Eastern Mediterranean Deep Water (tEMDW), are part of the extensive mixing regime between EMDW and LIW, with contributions of intermediate waters formed in the Aegean Sea. It is mostly the tEMDW that contributes to the TDW, while much of the LIW leaves the sea via the Sardinian Passage and the rather shallow Corsican Channel ( $\sim 450 \mathrm{~m}$ sill) in the north. These outflows at the same time incorporate part of the volcanic ${ }^{3} \mathrm{He}$ mentioned above because the depth ranges are similar. Hopkins (1988) reported a ratio of WMDW to Sicily Strait overflow waters of 2:1 on average and estimated the Sicily Strait input as 7 $10^{4} \mathrm{~m}^{3} \mathrm{~s}^{-1}$ (0.07 Sverdrup; Sv). Millot (1999) notes that the cascading on the northern slope of Sicily in the southern Tyrrhenian is a dominant mixing process between the Sicily Strait overflow and the WMDW. He also holds that the implied lifting of the WMDW is a prerequisite for the WMDW to eventually take part in the Strait of Gibraltar outflow. He believes that therefore the "Tyrrhenian Sea is a key place for the working of the whole Western Mediterranean Sea", and that by its action the Western Mediterranean (hereafter WMed) deep waters have a faster turnover than those of the EMed. A further point of his is that the mixing should increase with the WMDW inflow rate. He notes that beyond the cascading depth of about $2000 \mathrm{~m}$, WMDW should be predominant. The subsurface waters of the Mediterranean have been subject to slow increases in temperature and salinity (e.g., Bethoux et al., 1998); a summary for the WMed including the Tyrrhenian has been given by Fuda et al. (2002).

Millot (1999) furthermore characterizes the circulation within the Tyrrhenian as cyclonic at all depths (his Fig. 3), and as being concentrated toward the continental slopes. This implies that that the WMDW inflow would be concentrated toward the Sicilian slope and TDW outflow toward Sardinia. Zodiatis and Gasparini (1996) found that the Tyrrhenian Sea staircases have a clear and coherent structure in the interior of the deep basin, but become blurred toward the slopes. Because vertical exchange across the interfaces is rather slow, their interpretation is that the stair structure is maintained by lateral exchange with a deep boundary flow, supporting Millot's view. The authors furthermore noted a decrease in the number of T-S steps between 1973 and 1992.

The recent changes in the Tyrrhenian Sea have been studied, among others, by Astraldi et al. (2002) and Gasparini et al. (2005). The basic fact is that the EMT increased the density of the Sicily Strait overflow, with the salinity being highest during 1992-1993 and decreasing thereafter (Gasparini et al., 2005; Fig. 4). As their Figs. 7 and 10 show, the change 
began to be felt in the Sicily Strait and at the entrance into the Tyrrhenian in about 1992, and, according to Astraldi et al. (2002; Fig. 15), shortly thereafter also within the TDW. This precedes the changes in the EMed deep waters, which is natural since the intermediate waters were affected by the EMT earlier than the deeper EMDW, for which the massive influx from the Aegean only began in mid-1992 (Roether et al., 2007; Fig. 9). Consequently, the density contrast between 500 and $2000 \mathrm{~m}$ in the Tyrrhenian was lowered (Gasparini et al., 2005; Fig. 16), enhancing downward mixing. On the basis of temperature and salinity balances, the authors deduced an average Sicily Strait input rate, 1990-2000, of 0.3 Sv, a four-fold increase over the previous rate, with the input peaking in 1992 (their Fig. 15). Both studies find rising temperature and salinity in the interior of the sea in the depth range of the staircases, which means that the lateral exchange with the boundary current must be substantial. One expects that the enhanced Sicily Strait input and increasing density of the TDW would modify, and presumably reduce, the WMDW impact. The property changes in the LIW have been identified as a factor in inducing changes in the WMDW that were recently observed (Schröder et al., 2006).

LIW is formed in the northwestern Levantine Sea (east of the island of Rhodes). This water mass starts with tritiugenic ${ }^{3} \mathrm{He}$ corresponding to a few years of ingrowth, and significant further ingrowth occurs during the several-year subsurface travel time up to the Sicily Strait (Roether et al., 1998a). Travel times can vary due to reversals of the upper circulation in the Ionian Sea, and it appears that in the years around 1987 these were comparatively long and became shorter in about 1997 (Gacic et al., 2010).

Tritium observations in the Tyrrhenian exist since 1972. Cortecci et al. (1974) reported for that year about $10 \mathrm{TU}$ at the surface (1 TU means a ${ }^{3} \mathrm{H} / \mathrm{H}$ ratio of $10^{-18}$ ), 4-6 TU in LIW, and 2.7 TU in TDW, while the corresponding values in 1981 were 6.5 TU, 5.5 TU, and 2.7 TU (Andrie and Merlivat, 1988); the latter values refer to the Sardinian Channel but should be near to those in the Tyrrhenian proper. The surface water values are compatible with the reconstruction for the Ionian Sea surface waters by Roether et al. (1992), i.e., maximum tritium in 1965 of approximately $28 \mathrm{TU}, 14 \mathrm{TU}$ in 1972, and 7 TU in 1981. The data suggest that subsurface tritium in the Tyrrhenian went through a broad maximum in the 1970s and has decreased since. Tritium and He isotope observations were carried out in 1997 (Rhein et al., 1999); the authors show that at that time the ${ }^{3} \mathrm{He}$ in the Tyrrhenian deep waters exceeded that in the WMed.

\section{Data and methods}

Table 1 lists the cruises that provided tritium, He isotope and neon (Ne) data used in this paper. All data prior to 2007 were measured at Bremen using the procedure of Sültenfuß et al. (2009). We report helium isotope ratios as $\delta^{3} \mathrm{He}(\%)$,
Table 1. The cruises providing data.

\begin{tabular}{lccr}
\hline Cruise & Dates & Tracer data $^{\mathrm{a}}$ & Reference \\
\hline MeteOR 5/6, & Aug-Sep 1987 & ++ & Roether et al. (2007) \\
MEteOR 31/1 & Jan-Feb 1995 & ++ & \\
Poseidon 234 & Oct-Nov 1997 & $++{ }^{\text {b }}$ & Rhein et al. (1999) \\
METEOR 44/4 & Apr-May 1999 & ++ & Roether et al. (2007) \\
METEOR 51/2 & Oct-Nov 2001 & ++ & \\
AEOLIAN '07 & Nov 2007 & + & Lupton et al. (2011) \\
MEdOCC07 & Oct 2007 & CTD $^{\text {c }}$ & \\
ETYMED & Jun-2009 & $\delta^{3}$ He only $^{\prime}$ & \\
\hline
\end{tabular}

a ++: tritium, $\delta^{3} \mathrm{He}, \mathrm{He}-$ and Ne-concentrations, T, S; + tritium and $\delta^{3} \mathrm{He}$ only.

$\mathrm{b}$ includes data for the tracer CFC-12

c courtesy K. Schröder and G. P. Gasparini.

which is the percentage deviation of the ${ }^{3} \mathrm{He} /{ }^{4} \mathrm{He}$ ratio from the atmospheric ratio. Typical precisions are about $\pm 0.2 \%$ for $\delta^{3} \mathrm{He}, \pm 0.3 \%$ for $\mathrm{He}$ and $\mathrm{Ne}$ concentration, and $\pm 3 \%$ or $0.01 \mathrm{TU}$ (whichever is greater) for tritium. For the 1987 cruise, tritium measurements were partly done by gas counting following isotopic enrichment, with typical precisions of 5\%/0.08 TU (cf. Roether et al., 1999). Data from the 2007 and 2009 cruises were measured in Newport, Oregon, using the procedure of Lupton (1990). Tritium was measured by mass spectrometer using the ${ }^{3} \mathrm{He}$ ingrowth method. Precisions are about $\pm 0.2 \%$ for $\delta^{3} \mathrm{He}$ and $\pm 0.03 \mathrm{TU}$ for tritium. The stations that we use below are shown in Fig. 1, which also outlines the bathymetry. Those in the Tyrrhenian are scattered throughout the basin, consequences are addressed below. Temperature and salinity, measured by CTD, have uncertainties for METEOR 5/6 and PoseIDON 234 of about $\pm 0.003^{\circ} \mathrm{C}$ and \pm 0.004 salinity units, but lower ones for MEDocc07. Depths are given in decibars $(1 \mathrm{dbar} \approx 0.99 \mathrm{~m})$ and density as potential density anomaly referenced to $2000 \mathrm{dbar}\left(\sigma_{2}\right)$.

The PosEIDON cruise has four Tyrrhenian stations with data for the named tracers, i.e., the full set at Stas. 745 and 764 , tritium only at 765 , and the He/ $\mathrm{Ne}$ set only at 766 . That station is located near to the center of the deep part of the basin, while Sta. 764 has a rather more peripheral location. To enable evaluation of the former station, we use the fact that tritium concentrations should be rather well correlated with those of the transient tracer CFC-12. We therefore set $c_{\text {tri }}(766)=c_{\mathrm{CFC}-12}(766) c_{\text {tri }}(765) / c_{\mathrm{CFC}-12}(765)$, where the Sta. 765 ratios are interpolated to Sta. 766 bottle depths.

The tritium- ${ }^{3} \mathrm{He}$ age can be derived as follows:

$\tau=t_{1 / \mathrm{e}} \ln \left(1+{ }^{3} \mathrm{He}_{\text {tri }} /\right.$ tritium $)$

where, $t_{1 / \mathrm{e}}=$ radioactive mean life of tritium (17.8 years), and both tritium and ${ }^{3} \mathrm{He}_{\text {tri }}$, the tritiugenic ${ }^{3} \mathrm{He}$, are in TU ( $1 \mathrm{TU}, \mathrm{a}^{3} \mathrm{H} / \mathrm{H}$ ratio of $10^{-18}$; it is equivalent to $2.49 \times 10^{-15}$ ccSTP ${ }^{3} \mathrm{He}$ per $\mathrm{g}$ of water). Under Mediterranean conditions, $\mathrm{a}^{3} \mathrm{He}$ concentration in equilibrium with the atmosphere corresponds to $21 \mathrm{TU}$ of decayed tritium. Since ${ }^{3} \mathrm{He}_{\text {tri }}$ is lost at 


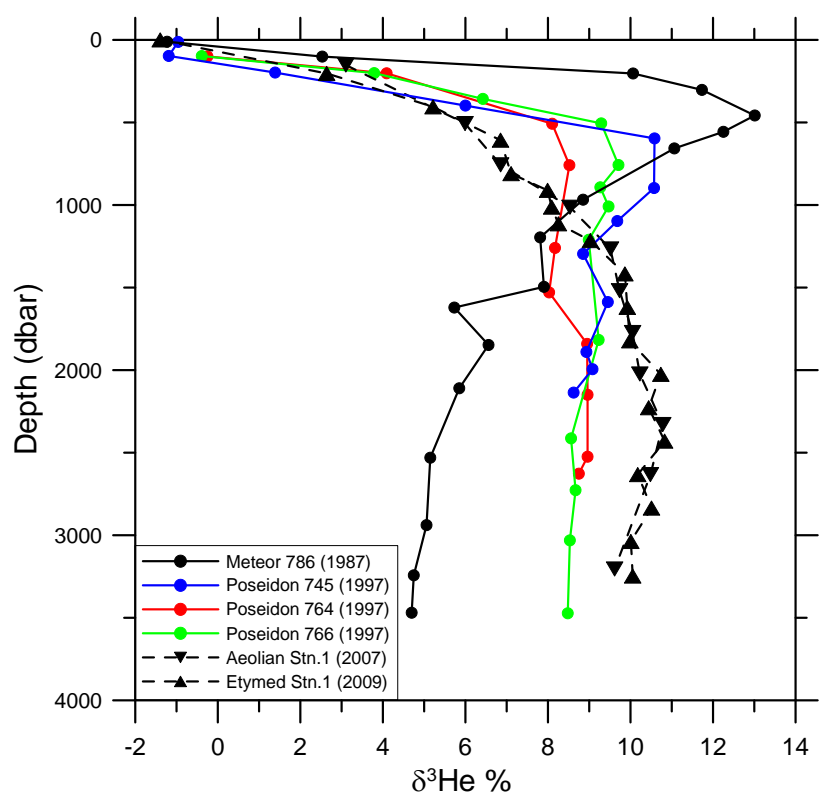

Fig. 2. $\delta^{3} \mathrm{He}$ versus depth in 1987 (METEOR cruise 5/6), 1997 (POSEIDON cruise 234) and 2007/2009 (AEOLIAN 07 and ETYMED). For cruises see Table 1 and for station positions see Fig. 1. $\delta^{3} \mathrm{He}$ is defined as the relative deviation $(\%)$ from the atmospheric ${ }^{3} \mathrm{He} /{ }^{4} \mathrm{He}$ ratio. Due to different solubility of the two isotopes (cf. Sect. 1$), \delta^{3} \mathrm{He}$ has surface values near $-1.6 \%$.

the water surface by the aforementioned equilibration with atmospheric $\mathrm{He}, \tau$ refers to uninterrupted subsurface travel. However, due to mixing effects, $\tau$ is biased toward components of relatively higher tritium and ${ }^{3} \mathrm{He}_{\text {tri }}$ concentrations. To determine ${ }^{3} \mathrm{He}_{\text {tri }}$, we apply the procedure of Roether et al. (1998b) with the correction of Roether et al. (2001; see also Well et al., 2001), which is based on measured He and $\mathrm{Ne}$ concentrations; for the AEOLIAN station of 2007, we used $\mathrm{He}$ and $\mathrm{Ne}$ concentrations estimated from the Bremen data of the other years. The procedure uses Ne observations to determine the atmosphere-derived portions of the He isotope concentrations. The remaining ${ }^{4} \mathrm{He}$ represents the portion released from the ocean floor (terrigenic $\mathrm{He}$ ), while the ${ }^{3} \mathrm{He}$ is composed of both terrigenic and tritiugenic ${ }^{3} \mathrm{He}$. The terrigenic ${ }^{3} \mathrm{He}$ is the product of the terrigenic $\mathrm{He}$ and its isotopic ratio $R_{\mathrm{t}}$ and can thus be corrected for provided that $R_{\mathrm{t}}$ is known.

Contrary to the high $R_{\mathrm{t}}$ values for He released from the Earth's deep interior, those for He derived from the Earth's crust are on the order of $R_{\mathrm{t}} / R_{\mathrm{a}}=0.1$ only. While the former component has localized sources, the latter is added at basin scale (Well et al., 2001). Terrigenic He in the Eastern Mediterranean has been shown to have a rather low ratio, $R_{\mathrm{t}} / R_{\mathrm{a}}=0.42 \pm 0.1$ (Roether et al., 1998b). Its prominent crustal contribution results from continental-type crust and excessive sediment load (Morelli, 1985). In the WMed similar conditions hold, and we therefore assume that a similarly

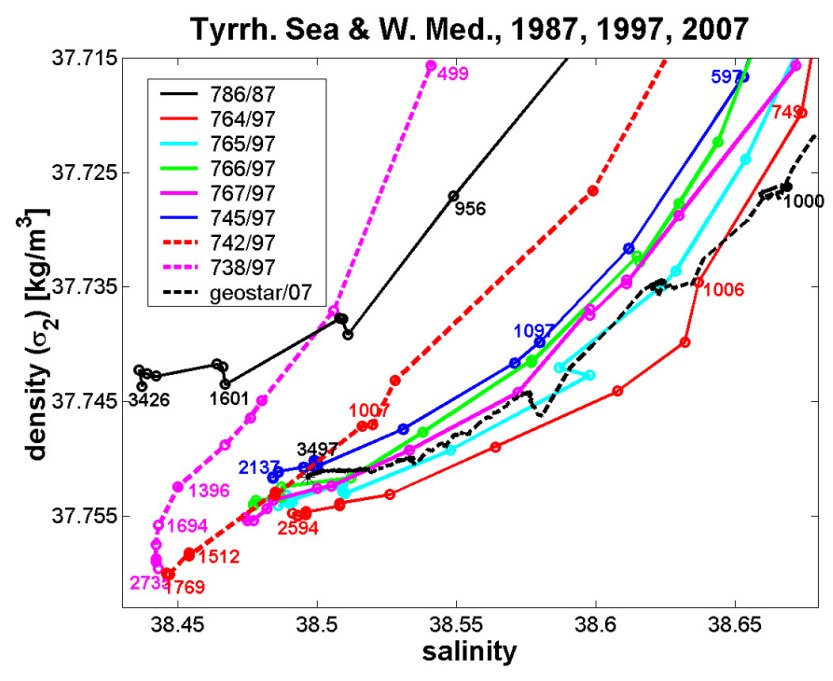

Fig. 3. Density $\left(\sigma_{2}=\right.$ potential density anomaly referenced to 2000 dbar) versus salinity for Tyrrhenian stations, 1987-2007 and for WMed stations of 1997 (bottle data; the 1997 profiles are in color). For cruises and station positions see Table 1 and Fig. 1, depth markings are in dbar. For the 2007 tracer station a nearby CTD profile is shown (MEDOCC07, see Table 1), which displays staircase structures.

low $R_{\mathrm{t}}$ is applicable. The Tyrrhenian waters are thus a mixture of low- $R_{\mathrm{t}}$ waters. Although the aforementioned volcanic releases have a far higher $R_{\mathrm{t}}$, this input is at shallow depths and is partly removed with the LIW outflow. Furthermore the Tyrrhenian has a comparatively short turnover time, which limits the contributions from within the sea. On this basis, we use rounded $R_{\mathrm{t}} / R_{\mathrm{a}}$ values of 1 for the Tyrrhenian waters (assumed uncertainty \pm 0.5 ) and 0.5 outside.

It follows that the corresponding contributions of terrigenic ${ }^{3} \mathrm{He}$ to the total non-atmospheric ${ }^{3} \mathrm{He}$ amount to only about $15 \%$ within the Tyrrhenian and $7 \%$ outside. The uncertainties in measurement and in $R_{\mathrm{t}}$ convert to standard precisions of tritiugenic ${ }^{3} \mathrm{He}$ of about $\pm 0.2 \mathrm{TU}$. The age uncertainties are about \pm 3 years, or up to \pm 6 years in the case of low tritium concentrations measured by gas counting (i.e., for part of the deep Tyrrhenian values of 1987).

\section{Results and discussion}

The Tyrrhenian $\delta^{3} \mathrm{He}$ profiles shown in Fig. 2 reveal drastic changes over the period 1987-2009. The upper-layer values decrease steadily in time while the deep-water values rise, with a cross-over point near $1000 \mathrm{~m}$ depth. The figure gives a vivid illustration of the EMT-associated downward transfer of upper waters. As previously mentioned, such transfer lasted from about 1990 to 2000 (Sect. 2), so that the 1997 profiles fall into the active period, while those of 1987, 2007 and 2009 met more quiet conditions. It is thus no surprise that the 1997 profiles show significant differences, 


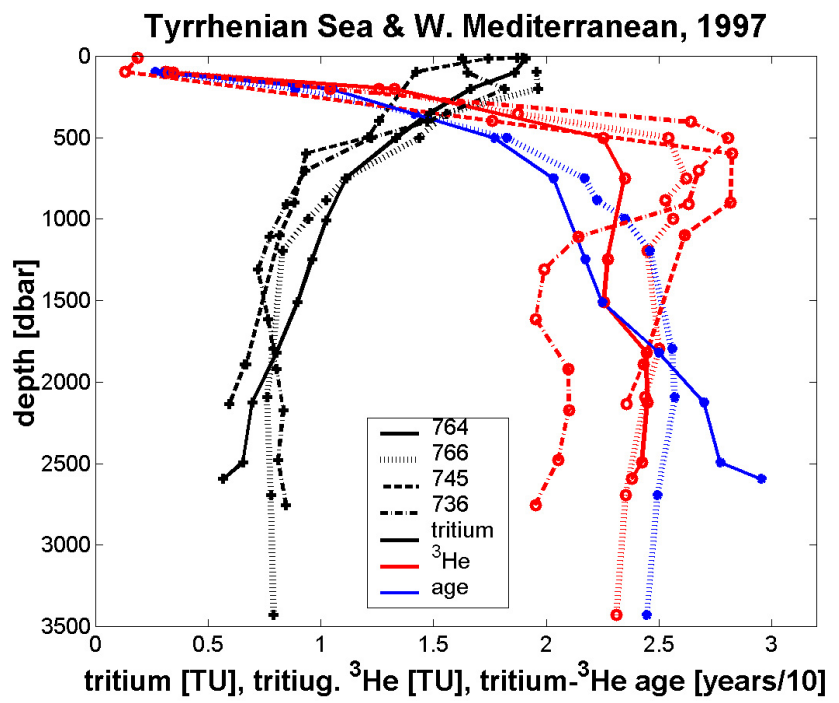

Fig. 4. Profiles of tritium and tritiugenic ${ }^{3} \mathrm{He}$ (both in TU) and of tritium ${ }^{3} \mathrm{He}$ ages (Stas. 764 and 766 only) in the Tyrrhenian Sea and the WMed, PosEIDON 234, 1997. Note that age scale is compressed 10 -fold ( 1 unit $=10$ years). For station positions see Fig. 1. Sta. 736 in the WMed replaces 738 shown in Fig. 3 which does not have tracer data, while $\mathrm{T}$ and $\mathrm{S}$ are nearly the same. Tritium data for station 766 converted from Sta. 765 data using a correlation with the tracer CFC-12 (Sect. 3).

while those of 2007 and 2009 are virtually identical; we infer that the single profile of 1987 should be rather characteristic for the Tyrrhenian at large.

The question of uniformity within the Tyrrhenian in 1997 and of water exchange with the WMDW is addressed in Fig. 3, which presents density $\left(\sigma_{2}\right)$ versus salinity for Tyrrhenian and WMed stations from the 1997 cruise (all in color), together with relationships for the 1987 and 2007 Tyrrhenian stations (black). Bottle data are shown to ease a comparison to the corresponding tracer profiles in Fig. 4. Sta. 738 represents the WMed waters that potentially enter the Tyrrhenian, while Sta. 742, at the slope in the far southwest of Sardinia (Fig. 1), represents the mixture, moving northward, of original WMDW and TDW outflow from the Tyrrhenian close to the entry of the latter. Of the Tyrrhenian stations, the 1987 profile has by far the lowest densities, reflecting the differing characteristics of WMDW (Bethoux et al., 1998) and the lesser input of Sicily Strait overflow waters prior to the EMT-based changes. This situation should have prevailed up to about 1992 (Sect. 2). Among the 1997 stations, Sta. 745 (blue) is the closest to the 1987 profile and 764 (red) the farthest, which is caused by delayed arrival of the modified waters at the former station, in keeping with the mentioned cyclonic circulation in the basin. In the TDW depth range (1000-2000 m), the spread between these two stations in $\sigma_{2}$-salinity space amounts to about $1 / 3$ of their mean distance to the 1987 station properties. As these differences

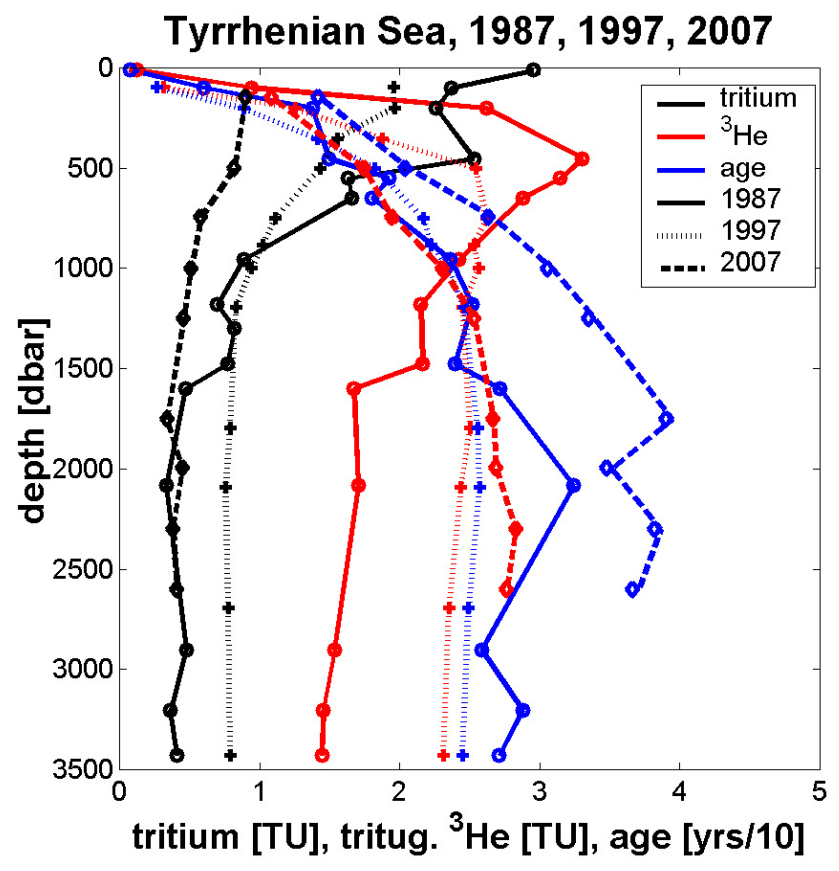

Fig. 5. Tritium, tritiugenic ${ }^{3} \mathrm{He}$ [TU] and tritium- ${ }^{3} \mathrm{He}$ age [years/10] in the Tyrrhenian Sea in 1987 (M 5/6, Sta. 786, full lines), 1997 (PosEIDON 234, Sta. 766, dotted) and 2007 (AEOLIAN 07, V07B01, dashed). For station positions see Fig. 1. The scatter in the 1987 tritium profile and in the age profiles reflects the data uncertainties (Sect. 3).

refer to a period of about 5 years (1992-1997), they point to a characteristic, or e-folding, time for internal TDW recirculation of $\tau_{\text {recirc }} \approx 5$ years. This is but a rough estimate, although the corresponding distances in T-S space (not shown) give a similar result. Older waters might however be present east of $12^{\circ} \mathrm{E}$, i.e., halfway across the basin (Fig. 1), outside of the eastern along-slope current band, for which we have no tracer information. These waters might be lower in tritium than found at our Tyrrhenian tracer stations. We hold that, therefore, and also in view of its rather central position in the basin, Sta. 766 is a reasonable choice to represent the deep Tyrrhenian basin in 1997 (cf. Fig. 5).

The 2007 Geostar profile (see Table 1), matches the $\sigma_{2}$ salinity range of the 1997 Tyrrhenian stations below about $1100 \mathrm{~m}$, while at shallower depths it deviates toward higher salinity. Near the bottom, the 2007 profile has higher salinity and is on the low side of the 1997 densities, indicating that WMDW influx in the years in-between must have been rather limited. We note in passing that at this station the staircase structure between about 1000 and $2000 \mathrm{~m}$ depth is rather similar to that found in 1992 (Zodiatis and Gasparini, 1996), but, naturally, with temperature and salinity distinctly higher than observed in that year.

As for the prominence of WMDW in the deepest Tyrrhenian waters noted by Millot (1999), the 1987 Sta. 786 indeed 
has a near-homogeneous bottom layer reaching up to $2500 \mathrm{~m}$ depth. However, similar features in the 1997 Tyrrhenian profiles are restricted to below $3000 \mathrm{~m}$ depth. This indicates that in 1997 the WMDW had less prominence than prior to the period of enhanced vertical transfer.

The property values in the boundary flow west of Sardinia (Sta. 742) contrast strongly with those farther west (Stas. 736 and 738). Assuming that the addition of TDW occurs primarily along isopycnals, the higher salinities indicate TDW contributions of $60 \%$ or more on average, approaching $100 \%$ near $1200 \mathrm{~m}$ depth. Prior to the EMT-induced changes, the boundary flow certainly had lower salinity, a consequence of the comparatively lower salinity of the WMDW and its larger contribution to the TDW (Sect. 2). Considering the enhanced influx of Sicily Strait overflow under EMT influence (1990-2000 average 0.3 Sv; Sect. 2), the WMDW contribution to the TDW, and WMDW entrainment upon passing the Sardinian Passage, the boundary flow along Sardinia definitely exceeded $0.5 \mathrm{~Sv}$ over several years. It follows that this flow represented a distinct input of high-salinity waters directly into the deep-water depth range, which to our knowledge has escaped the attention in previous studies.

Figure 4 compares tracer profiles of the 1997 Stas. 764, 766, 745, and 736, in correspondence to Fig. 3. Sta. 766 (dotted) reaches the deepest and displays rather uniform property values below $1500 \mathrm{~m}$. Below $750 \mathrm{~m}$, the Sta. 766 tritium values become intermediate between those at Stas. 745 (dashed) and 764 (full lines) but exceed these below $1900 \mathrm{~m}$. Tritiugenic ${ }^{3} \mathrm{He}$ at Sta. 766 is likewise intermediate at mid depths, while at $1800 \mathrm{~m}$ the three stations nearly coincide, and the Sta. 766 tritium- ${ }^{3} \mathrm{He}$ ages exceed those at Sta. 764 down to $2000 \mathrm{~m}$, while at greater depths they are markedly lower. Above we pointed out that Sta. 764 has the shortest path from the cascading region, which is consistent with its comparatively lower ${ }^{3} \mathrm{He}$ and lower ages down to about $1800 \mathrm{~m}$. But at greater depths apparently older waters are present, which is manifested in lower tritium and higher ${ }^{3} \mathrm{He}$ and ages. Sta. 736 (dash-dotted) in the WMed has the lowest tritium of the set at mid-depth $(\sim 800-1500 \mathrm{~m})$, but the highest below $1800 \mathrm{~m}$, while its ${ }^{3} \mathrm{He}$ is the lowest from $\sim 800 \mathrm{~m}$ all the way to the bottom. At Sta. 742 at the southwestern slope of Sardinia one finds tritium and ${ }^{3} \mathrm{He}$ values (not shown) rather similar to those at Sta. 736, in particular similarly low ${ }^{3} \mathrm{He}$ below $800 \mathrm{~m}$.

The temporal evolution of the tracer profiles for the Tyrrhenian is shown in Fig. 5. The tritium and ${ }^{3} \mathrm{He}$ profiles fully support the downward water transfer noted in Fig. 2. The cross-over depth between the 1987 and 1997 profiles is near $900 \mathrm{~m}$, very similar to that in Fig. 2, while below $1500 \mathrm{~m}$ the tritium became uniformly higher by two-fold down to the bottom. The ages hardly changed down to $1500 \mathrm{~m}$ and became lower farther down. After 1997, tritium decreased by decay, raising the ${ }^{3} \mathrm{He}$ values, which, according to Eq. (1), led, below $1200 \mathrm{~m}$, to an apparent $\sim 10$-year increase in age up to 2007 , i.e., just about the difference in calendar time.

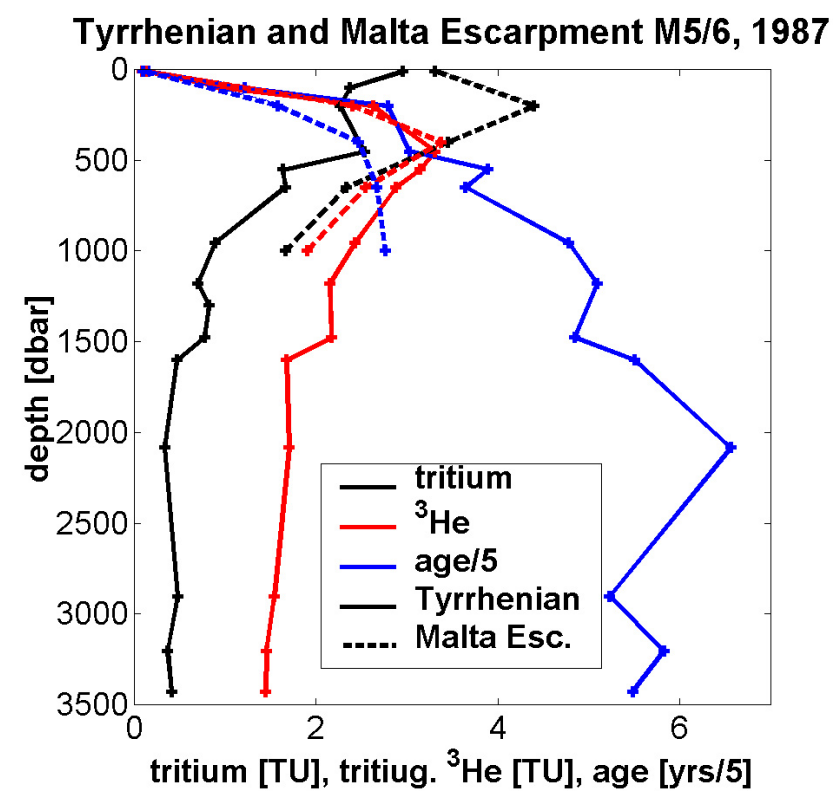

Fig. 6. Profiles of tritium, tritiugenic ${ }^{3} \mathrm{He}$ [TU] and tritium- ${ }^{3} \mathrm{He}-$ ages [years/5], Meteor 5/6, 1987, in the Tyrrhenian Sea (Sta. 786) and at the Malta Escarpment upstream of the Sicily Strait (Sta. 779). For Sta. 779 only the upper $1000 \mathrm{~m}$ are shown, for station positions see Fig. 1.

Before discussing Fig. 5 in more detail, we address the connection to the Sicily Strait overflow. Figure 6 compares the Tyrrhenian tracer profiles of 1987 with concurrent ones at the Malta Escarpment immediately upstream of the strait. Considering uplift of the waters upon entrance into the strait (Astraldi et al., 2001), the relevant depth range at the escarpment feeding the Tyrrhenian should be approximately 350$550 \mathrm{~m}$. It follows that tritiugenic ${ }^{3} \mathrm{He}$ hardly increased on the way, tritium decreased, and the ages increased from about 12 to 15 years at the Sicily overflow depths. These changes are clearly attributable to tritium decay and ${ }^{3} \mathrm{He}$ ingrowth during the transit, accompanied by dilution. The consistency between the tracer profiles provides independent evidence of the ${ }^{3} \mathrm{He}$ in the Tyrrhenian arising predominantly from tritium decay.

In the upper-water column of the Tyrrhenian Sea, tritiugenic ${ }^{3} \mathrm{He}$ and tritium continually decreased in time (Fig. 5), but this is only partly due to convective mixing in the Tyrrhenian. A further cause is a decrease in the supply from the Sicily Strait. At the Malta Escarpment (Fig. 7) in the relevant depth range (350-550 $\mathrm{m}$, see above), the tritium $\left({ }^{3} \mathrm{He}\right)$ values were $3.5 \mathrm{TU}$ (3.2 TU) in 1987 and $1.3 \mathrm{TU}$ (2.1 TU) in 2001. In detail one notes inversions between 1995 and 1999 in ${ }^{3} \mathrm{He}$ and between 1999 and 2001 in tritium. The 1999 profile displays the highest ${ }^{3} \mathrm{He}_{\text {tri }}$ /tritium ratio in the set. Possible causes are the aforementioned inversions in the Ionian circulation (Sect. 2) or effects from the differing station positions. The 2007 upper water tritium and ${ }^{3} \mathrm{He}_{\text {tri }}$ values in the Tyrrhenian Sea (Fig. 5) were about 0.8 and 2.1 TU. Considering 


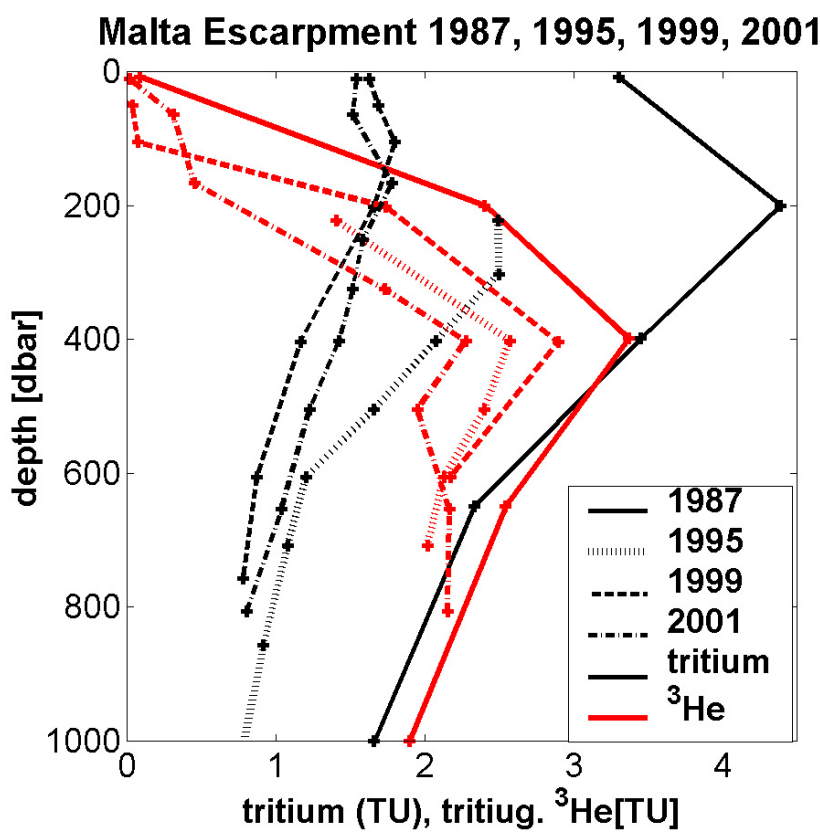

Fig. 7. Profiles of tritium and tritiugenic ${ }^{3} \mathrm{He}$ off the Malta Escarpment in 1987 (Meteor 5/6, Sta. 779), 1995 (METEOR 31/1, Sta. 8), 1999 (Meteor 44/4, Sta. 303) and 2001 (Meteor 51/2, Sta. 558). For station positions see Fig. 1. The locations of the 1999 and 2001 stations are somewhat farther away from the escarpment. Note temporal inversions in the general trend of decreasing tracer concentrations.

the decreasing tritium values in the overflow and decay after 2001, the 2001 Malta Escarpment and 2007 Tyrrhenian tracer values are fairly compatible.

Returning to Fig. 5, we noted above that in 1987 tritium was virtually constant below $1500 \mathrm{~m}$ down to $3500 \mathrm{~m}$, and was again constant but a factor of two higher in 1997. The uniformity of tritium in 1987 is indicative of relatively fast vertical mixing, unless the potential WMDW contributions accidentally resulted in matching tritium concentrations. Also for 1997, tritium might have been added at depth by intruding WMDW, but salinity increased so much during this period (Fig. 3) that such contributions must have been quite small. Between 1997 and 2007 one finds tritium below $1000 \mathrm{~m}$ depth dropping by $\sim 0.4 \mathrm{TU}$, i.e. by a factor of 2 , in agreement with 10 years of decay within the data errors. However, a matching ${ }^{3} \mathrm{He}$ increase is only present below $2000 \mathrm{~m}$, indicative of a closed system, i.e. of essentially stagnant resident waters. At shallower depths the ${ }^{3} \mathrm{He}$ increase is half as great or less. The cause is uncertain. Substantial ongoing transfer from above would have reduced the ${ }^{3} \mathrm{He}$ further and can thus be ruled out, and the same holds for contributions of WMDW (Fig. 4). A possibility could be admixture of Tyrrhenian deep waters from east of $12^{\circ} \mathrm{E}$, where, as mentioned above, waters could have been "older", having both lower tritium and ${ }^{3} \mathrm{He}$. Note that the similarity of the 2007 and 2009 deep-water $\delta^{3} \mathrm{He}$ values (Fig. 2) arises from the fact that by 2007 tritium had become so low ( $\sim 0.4 \mathrm{TU})$ that decay up to 2009 represented a rather insignificant $\delta^{3} \mathrm{He}$ increase $(0.15 \%)$.

\section{Conclusions}

${ }^{3} \mathrm{He}$ and tritium data in the Tyrrhenian Sea, in the EMed immediately upstream of the Sicily Strait, and in the WMed, 1987-2009 (Figs. 2 and 5), give independent evidence of the EMT-related enhanced mixing of the waters overflowing the Sicily Strait into the Tyrrhenian Sea deep waters, supporting previous studies (e.g., Astraldi et al., 2002; Gasparini et al., 2005). The data reflect the downward cascading of the inflowing waters from the Sicily Strait in the southern Tyrrhenian Sea, which, according to Sparnocchia et al. (1999) and Millot (1999), should reach down to about $2000 \mathrm{~m}$ depth. In 1987 there was a thick bottom layer, depth $2500-3500 \mathrm{~m}$, which showed near-constant temperature and salinity, while in 1997 such a layer did not reach above $3000 \mathrm{~m}$ depth. We interpret the increased depth of the top of this layer, together with other evidence (see above), as indicating a reduced impact of WMDW on the Tyrrhenian deep waters during the period of enhanced mixing. It follows that less WMDW was involved in the cascading within the sea compared to outside this period. According to Millot (1999) this means a reduced upward displacement of WMDW, reducing its capability to leave the WMed via Gibraltar Strait. The tracer concentrations, on the other hand, were virtually constant below 1200 to $1500 \mathrm{~m}$ in both cases. This finding points to relatively fast mixing beyond the depth of the cascading. For 1997 we note substantial horizontal differences in deep-water tracer concentrations, which support the cyclonic nature of the circulation (Millot, 1999) and indicate a time scale for horizontal exchange within the sea on the order of 5 years. We furthermore find that the TDW outflow must, for several years, have served as major source of waters of enhanced salinity and density in the deep-water depth range of the WMed.

Our study furthermore confirms that the deep ${ }^{3} \mathrm{He}$ maximum observed by Lupton et al. (2011) was indeed almost entirely produced by tritium decay. The conditions for ingrowth of tritiugenic ${ }^{3} \mathrm{He}$ are favorable, since the waters overflowing in the Sicily Strait have long subsurface travel times from their formation regions, and once the waters have been transferred into the Tyrrhenian deep waters, further ingrowth can freely occur. The separation of tritiugenic ${ }^{3} \mathrm{He}$ followed a procedure described elsewhere (Roether et al., 1998b, 2001), which makes use of concurrent $\mathrm{He}$ and $\mathrm{Ne}$ concentration data. Under the special conditions of the Mediterranean Sea there is, fortunately, much less interference by ${ }^{3} \mathrm{He}$ released from the ocean floor than elsewhere in the ocean (Roether et al., 1998b; Well et al., 2001). Furthermore, the volcanic ${ }^{3} \mathrm{He}$ observed by Lupton et al. (2011) is released at rather shallow depths, so that much of it is removed with the LIW outflow from the Tyrrhenian Sea. 
Acknowledgements. The METEOR cruises and part of the tracer measurements at Bremen were funded by the Deutsche Forschungsgemeinschaft, Bonn-Bad Godesberg, Germany. Further support was received by various grants of the European Union, Brussels, Belgium. We are grateful for the assistance of the masters and crew of the various cruises and for the efforts of numerous helpers at sea and in our laboratories, without whom the present study would not have been possible. We thank Monika Rhein, Bremen, principle investigator of the POSEIDON 234 cruise, for providing data, and Katrin Schröder and Gian Pietro Gasparini, Pozzuolo di Lerici, for the CTD data from their 2007 Geostar station and for useful commentary. Leigh Evans and Ron Greene carried out the tracer measurements in Newport, and that work was supported by the NOAA Vents Program. We thank Mario Sprovieri and Angelo Bonanno for sampling on the Etymed expedition, and Sharon Walker for assistance with the CTD data. This is PMEL publication No. 3592.

Edited by: N. Pinardi

\section{References}

Andrie, C., and Merlivat, L.: Tritium in the western Mediterranean during the 1981 Phycemed cruise, Deep-Sea Res. I, 35(2), $247-$ 267, 1988 .

Astraldi, M., Gasparini, G. P., Sparnocchia, S., Moretti, S., and Sansone, E.: The characteristics of the Mediterranean water masses and the water transport in the Sicily Channel at long time scales, in: Dynamics of Straits and Channels, edited by: Briand, F., CIESM Science Series, Monaco, 2, 95-118, 1996.

Astraldi, M., Gasparini, G. P., Gervasio, L., and Salusti, E.: Dense water dynamics along the Strait of Sicily (Mediterranean Sea), J. Phys. Oceanogr., 31, 3457-3475, 2001.

Astraldi, M., Gasparini, G. P., Vetrano, A., and Vignudelli, S.: Hydrographic characteristics and interannual variability of water masses in the central Mediterranean: a sensitivity test for long-term changes in the Mediterranean Sea, Deep-Sea Res. I, 49, 661-680, 2002.

Béthoux, J.-P.,Gentili, B., and Tailliez, D.: Warming and freshwater budget change in the Mediterranean since the 1940s, their possible relation to the greenhouse effect, Geophys. Res. Lett., 25(7), 1023-1026, 1998.

Clarke, W. B., Jenkins, W. J., and Top, Z.: Determination of tritium by mass spectrometric measurement of ${ }^{3} \mathrm{He}$, Int. J. Appl. Radiat. Isotopes, 27, 515-522, 1976.

Cortecci, G., Molcard, R., and Noto, P.: Isotopic analysis of the deep structure in the Tyrrhenian Sea, Nature, 250, 134-136, 1974.

Fuda, J.-L., Etope, G., Millott, C., Favali, P., Calcare, M., Smriglio, G., and Boschi, E.: Warming, salting and origin of the Tyrrhenian Deep Water, Geophys. Res. Lett., 29(19), 1898, doi:10.1029/2001GL014072, 2002.

Gacic, M., Borzelli, G. L. E., Civitarese, G., Cardin, V., and Yari, S.: Can internal processes sustain reversals of the ocean upper circulation? The Ionian Sea example, Geophys. Res. Lett., 27, L09608, doi:10.1029/GL043216, 2010.
Gasparini, G. P., Ortona, A., Budillon, B., Astraldi, M., and Sansone, E.: The effect of the Eastern Mediterranean Transient on the hydrographic characteristics in the Strait of Sicily and in the Tyrrhenian Sea, Deep-Sea Res. I, 52, 915-935, 2005.

Hopkins, T. S.: Recent observations in the intermediate and deep water circulation in the Southern Tyrrhenian Sea, Oceanol. Acta, 9, 41-50, 1988.

Lucas, L. L. and Unterweger, M. P.: Comprehensive review and critical evaluation of the half-life of tritium, J. Res. Natl. Inst. Stand. Tech., 105(4), 541-549, 2000.

Lupton, J. E.: Water-column hydrothermal plumes on the Juan de Fuca Ridge, J.Geophys. Res., 95, 12829-12842, 1990.

Lupton, J., de Ronde, C., Sprovieri, M., Baker, E. T., Bruno, P. P., Italiano, F., Walker, S., Faure, K., Leybourne, M., Britten, K., and Greene, R.: Active hydrothermal discharge on the submarine Aeolian Arc, J. Geophys. Res., doi:10.1029/2010JB007738, in press, 2011.

Millot, C.: Circulation in the Western Mediterranean Sea, J. Mar. Systems, 20, 423-442, 1999.

Morelli, C.: Geophysical contribution to knowledge of the Mediterranean crust, in: Geological Evolution of the Mediterranean Basin, edited by: Stanley, D. J. and Wenzel, F.-C., Springer Verlag, New York, 65-82, 1985.

Rhein, M., Send, U., Klein, B., and Krahmann, G.: Interbasin deep water exchange in the western Mediterranean, J. Geophys. Res., 104(C10), 23495-23508, 1999.

Roether, W., Schlosser, P., Kuntz, R., and Weiss, W.: Transienttracer studies of the thermohaline circulation of the Mediterranean, in: Winds and Currents of the Mediterranean Basin, Proc. NATO workshop "Atmospheric and Oceanic Circulations in the Mediterranean Basin”, 7-14 September 1983, Santa Teresa, Italy, edited by: Charnock, H., Harvard University, Cambridge MA, II, 291-317, 1992.

Roether, W., Klein, B., Beitzel, V., and Manca, B. B.: Property distributions and transient-tracer ages in Levantine Intermediate Water in the Eastern Mediterranean, J. Mar. Systems, 18, 71-87, 1998a.

Roether, W., Well, R., Putzka, A., and Rüth, C.: Component separation of oceanic helium, J. Geophys. Res., 103, 27931-27946, 1998 b.

Roether, W., Beitzel, V., Sültenfuß, J., and Putzka, A.: The Eastern Mediterranean tritium distribution in 1987, J. Mar. Systems, 20, 49-61, 1999.

Roether, W., Well, R., Putzka, A., and Rüth, C.: Correction to "Component separation of oceanic helium", J. Geophys. Res., 106(C3), p. 4679, 2001.

Roether, W., Klein, B., Manca, B. B., Theocharis, A., and Kioroglou, S.: Transient Eastern Mediterranean deep waters in response to the massive dense-water output of the Aegean Sea in the 1990s, Prog. Oceanogr., 74, 540-571, doi:10.1016/j.pocean.2007.03.001, 2007.

Schröder, K., Gasparini, G. P., Tangherini, M., and Astraldi, M.: Deep and intermediate water in the western Mediterranean under the influence of the Eastern Mediterranean Transient, Geophys. Res. Lett., 33, L21607, doi:10.1029/2006GL027121, 2006.

Sparnocchia, S., Gasparini, G. P., Astraldi, M., Borghini, M., and Pistek, P.: Dynamics and mixing of the Eastern Mediterranean Outflow in the Tyrrhenian Basin, J. Mar. Syst., 20, 301-317, 1999. 
Sültenfuß, J., Roether, W. and Rhein, M.: The Bremen mass spectrometric facility for the measurement of helium isotopes, neon, and tritium in water, Isot. Environ. Healt. S., 45(2), 83-95, doi:10.1080/10256010902871929, 2009.
Well, R., Lupton, J., and Roether, W.: Crustal helium in deep Pacific waters, J. Geophys. Res., 106, 14165-14177, 2001.

Zodiatis, G. and Gasparini, G. P.: Thermohaline staircase formation in the Tyrrhenian Sea, Deep-Sea Res. I, 41(5), 655-678, 1996. 